\title{
What are students doing in our library? Ethnography as a method of exploring library user behaviour
}

\author{
Joanna Bryant
}

\begin{abstract}
The paper summarises an ethnographic study conducted at Loughborough University in 2007 which investigated user behaviour in a new open-plan learning environment. It seeks to encourage wider use of ethnography within library and information science research and recommends the method as a particularly effective way to explore how library space is used. The author encourages both practitioner-researchers and academics to consider using the method more frequently.
\end{abstract}

A more in depth discussion of the findings of the project appears in Bryant, Matthews \& Walton (2009), whilst the dissertation itself is available online (Bryant, 2007).

\section{Introduction}

For many practitioners, their Masters' dissertation is their first experience of undertaking a structured piece of library and information science (LIS) research. Once working full time, research is sometimes seen as a 'luxury' as the competing demands of the workplace take precedence. Indeed, LIS research has often been criticised for having a significant research-practice gap. Booth (2003) comments that "practitioner-led research is criticised for its lack of rigour, academic research for its lack of relevance." In the present economic climate, there can be few library and information services that are not feeling pressure to retrench. It is, therefore, particularly timely that LIS professionals demonstrate the value of their skills and services. As Thornton (2008) explains, research is one of the best ways of doing this:

I have always been a strong advocate of being forearmed and demonstrating the value - perceived or actual - of what we do to a whole range of different

\section{Joanna Bryant}

Joanna Bryant graduated from Loughborough University in 2007 with an MSc in Information and Library Management. She is an Information Specialist in a government library.

Email: jothelibrarian@gmail.com 
stakeholders, but it is the senior management who must take priority. Any dumb cluck who forgets that is going to be without a Library to run in pretty quick time.

(Thornton, 2008, 36)

Good research can be an effective way of demonstrating to administrators and funding providers how their money is being used, and why continued investment is worthwhile.

This paper argues that ethnography, also known as participant observation, is an under-used but effective qualitative research method for both practitioners and academics. It summarises the findings of a small ethnographic study undertaken at Loughborough University in 2007. The approach was used successfully to investigate how a new, open plan learning environment in the university library was utilised by students. The findings were used to inform library management how investment in the fabric and furnishings of the library had impacted on student use of space. Whilst the project was undertaken by a student researcher (who also worked part-time in the library in question), the method is fairly simple and could certainly be used effectively by practitioners.

\section{Why use a qualitative method?}

Quantitative studies have an enduring popularity with librarians, since they can make good use of the wide range of readily available data such as library gatecounts, book issue figures etc. Such studies follow a relatively linear progression, from research design, to data collection, to data analysis. At the end, the researcher may produce a set of statistics, or graphs to convey their findings. Such graphs make regular appearances in library annual reports or briefing papers. According to Berg $(2007,2)$, much research has a bias towards quantitative methodologies which are given "more respect. This may reflect the tendency of the general public to regard science as relating to numbers and implying precision..." However, statistics and surveys can only go so far. For example, data from the Library and Information Statistics Unit (LISU) indicate that visits to UK academic libraries rose by over 15\% between 1995 and 2005 (LISU, 2006). Yet the number of visits per FTE student has fallen by $10 \%$ over the last five years (LISU, 2006). What does this mean for academic libraries? Such data cannot tell us how library buildings and resources are actually used. J.E. Davies, a former director of LISU, encourages practitioners and academics to make use of statistics, but also acknowledges the value of qualitative methods:

Simply counting things because they can be counted (and maybe, have always been counted) and then deciding what, if anything, to do with the results offers few opportunities for real services assessment and is a thing of the past. There is growing adoption of social measures, or 'soft indicators' to assess the influence of, and value added through particular initiatives or services. These are harder to analyse and interpret but can be used to advantage in charting the broader contribution of information and library services.

(Davies, 2002, 131)

For libraries seeking to evaluate the impact of investment in the fabric of their buildings, quantitative studies may not be the best approach. 
Ethnography is a form of participant observation most commonly utilised by anthropologists. Despite its ability to help answer that difficult question "what's going on?" ethnography is seldom used within LIS research. Hilder and Pym (2008) concluded that the method was used in just 3.7\% of papers published in high-profile LIS journals in 2005. The authors recommend that, amongst others, the ethnographic method is given more coverage in LIS doctoral programs in order to prepare academic researchers to utilise it in the field. Whilst full ethnographic studies typically demand a researcher undertake a protracted period of participant observation, a shorter approach can be used to some valuable effect. 'Ethnographically informed reports' offer a condensed approach, concentrating on particular spaces or points in time (Fetterman, 1998; Berg, 2007). In his influential text, Ethnography: a way of seeing (1999), Wolcott argues fervently that the dominance of quantitative methods should not be allowed to overshadow the merits of qualitative approaches:

Neophyte researchers indoctrinated so rigorously in rigor that they no longer appreciate or trust what each of us accomplishes through personal experience may need to be reminded of the human capacity for observation and to recognize that ultimately everything we know comes to us that way.

(Wolcott, 1999, 46)

Wolcott's argument, that observation is the sine qua non of knowledge, is a powerful one. It is certainly true that we can learn much from simple observation, yet this is an approach to research inquiry which is often overlooked, possibly because of its perceived simplicity. It is, in a sense, too obvious.

\section{The Loughborough University project}

Loughborough University's Pilkington Library opened its flexible learning space $\left(\right.$ Open $\left.^{3}\right)$ in 2005. This research project was undertaken in 2007 as a means of investigating how the space was being utilised. Flexible learning spaces like Open $^{3}$ are becoming commonplace across the academic sector, as libraries seek to respond to wider changes in higher education (HE) and student expectations. Historically universities taught by means of lectures and tutorials, and knowledge was tested by end-of-degree examinations. However, the structure and composition of HE has changed dramatically over the last fifty years, with growth in the number of institutions, and the number of students. The advent of tuition fees for UK students has led many to consider themselves the 'customers' of HE, rather than participants, and has 'marketized' universities (Fox, 2002). Teaching and assessment styles have altered in line with this transformation, with students now routinely producing collaborative work such as group projects, reports and presentations (Livingston and Lynch, 2000). New learning spaces in academic libraries seek to support this kind of learning by combining traditional library resources with electronic ones, and by providing spaces for collaborative work. Whilst library staff in many institutions have been successful in gauging user opinion on these spaces by means of satisfaction surveys, and quantitative analyses, there is hardly any published literature which uses ethnography/ participant observation as a method. 
The present study built upon an earlier user survey at Loughborough which explored how learners used library space, and their preferences for learning environments (Walton, 2006). One of that study's recommendations was that it would be beneficial to "identify precisely how Open ${ }^{3}$ is being used and capture the different types of learning that occurs there" (Walton, 2006, 145). The ethnographic approach was chosen for this project as an appropriate way to study the activities of library users without resorting to another survey. There was a general concern that undertaking such a study might lead to a limited response from library users (who had only recently participated in a survey). There was also an appreciation that surveys and interviews might lead respondents to provide the answers they felt were expected of them (Creaser, 2006). By conducting an observation-based study, it was felt that the library would obtain as unbiased a view of what was going on in Open ${ }^{3}$ as possible, without disturbing users.

A 'micro-ethnography' approach was used with data collected in phases. This meant that the library was studied at many different times of day, across several weeks. The researcher spent a total of 40 hours conducting fieldwork, recording observations in an electronic field-diary. Approval from the University's Ethics Committee was obtained before fieldwork commenced, and a notice was placed on the library website advising users of what was going on. The CILIP Code of Professional Practice (2007) was observed throughout the project. An initial pilot study was undertaken which established that using a laptop and word processing software to compile the field diary was more effective than taking notes longhand.

By the end of the project, the field diary was some 15,000 words in length. A grounded theory approach was used to analyse the diary and identify observation notes by theme (Strauss and Corbin, 1990). A selection of observation notes from the field diary are reproduced below in order to give a sense of the kind of activities the researcher observed taking place:

ON: ...The guys across the table from me are testing each other on statistical tests, and going over previous exam papers. They are really working together as a team. I'd never thought of maths as a team subject but they are clearly getting a lot out of working together.

(Field Notes, 06/06/2007, 10.45-12.45).

ON: ...A course mate comes over and says hello. We have a brief chat about dissertations... [she] asks me a question about questionnaire design. I don't know the answer, but the girl sat next to me (a stranger) has a think, and makes a useful suggestion.

(Field Notes, 06/06/2007, 20.45-23.00).

ON: ...Area seems very busy. At first glance, all the PCs are occupied but [many have been] abandoned by their users, left logged on. Frustrating!

(Field Notes, 15/05/2007, 15.30-19.00). 
ON: ..One of the library staff pops over for a chat, and asks how I am getting on. We exchange views about the space, and how the pizza boxes can be used as a metric to ascertain how busy it has been the night before. We both agree that Imago [who operate the library café] should start selling pizza. They are clearly missing a trick.

(Field Notes, 18/06/2007, 08.15-09.45).

Until this study was undertaken, library staff had no evidence to support their assumptions of what activities were taking place within Open ${ }^{3}$. Analysis of the field diary revealed that the space was being used as both a study and a social space. The findings of this study, combined with other investigations undertaken by the library in recent years indicate that users are largely satisfied with the provision of resources and learning spaces in the library. Users clearly appreciate the range of study environments available to them, with library statistics indicating that each area attracts a large number of visitors. It is clear that ongoing development of a range of different learning spaces is fundamental to the continued improvement of library services. However the study concluded that it is important to maintain the diversity of learning spaces available. Extending the open-plan learning space paradigm to other floors of the library was not recommended. However further investment in the furnishings of Open ${ }^{3}$ could lead to a more efficient use of the space. Simple suggestions, such as making sure computers left logged on but idle automatically reboot, thereby allowing another student to use them might help facilitate more effective use of the area. The study also indicated that mature students, and female students, were under-represented. Whilst the design of this study prevents any firm conclusions regarding the diversity of library users, this may be an area that the library management team wishes to explore further using an alternative methodological approach, such as a targeted survey. This would allow the library to investigate how far it is meeting the needs of different user groups.

\section{Reflections on the methodology}

Most of the data collection for this study took place during June 2007 when the library was trialling 24-hour opening. This period is one of the busiest times of the year for the library, when undergraduate students are revising for their exams. Some observation was conducted during the vacation period, but data saturation was reached fairly rapidly as the library was generally much less busy. The vacation observation phase was postponed for a time whilst $\mathrm{Open}^{3}$ was recarpeted and new electrical outlets were installed. This certainly had an impact on library usage during July, requiring anyone visiting to conduct their work on other floors of the building. It is impossible to establish how far study-habits developed during this period influenced library users over the summer. These factors are important to bear in mind as they have implications for the kind of activities taking place in the library. Had the study been conducted at a different point in the academic year, the results might have been markedly different. To gain a deeper 
understanding of how the university community uses Open ${ }^{3}$ it would be necessary to undertake further studies at different junctures in the academic year.

This project used only one researcher, yet was successful in eliciting a number of useful conclusions which have helped inform library management on how the open plan study space was being used. It was possible to reassure staff that the space is being used effectively for study and not purely for social exchange (although the latter is certainly an important function of the space). The project also generated some simple, but useful, ideas for improving services. As Sturges (2008) argues so passionately:

there is a great deal that can be done, and done well, in LIS research using simple, inexpensive methods. Qualitative research can tell us most of what we need to know on some topics, and this information can be obtained using quite informal techniques.

(Sturges, 2008,33)

Any LIS researcher, be they academic or practitioner (or indeed, both) can use ethnography to help them explore what users are actually doing in their library. It is simply necessary to find the time, and learn how to 'see' again, essentially to observe deliberately and carefully. The results can be surprising, and insightful.

\section{References}

Berg, B.L. (2007) Qualitative Research Methods for the Social Sciences, Boston, Pearson.

Booth, A. (2003) Bridging the research-practice gap? The role of evidence based librarianship, New Review of Information and Library Research 9(1), 3-23.

Bryant, J.E. (2007) An ethnographic study of user behaviour in Open ${ }^{3}$ at the Pilkington Library, Loughborough University. MSc dissertation, Loughborough University. URL: http://hdl.handle.net/2134/3136 [Accessed 21.12.2008].

Bryant, J.E. Matthews, G., and Walton, G. (2009). Academic libraries and social and learning space: A case study of Loughborough University Library, UK, Journal of Librarianship and Information Science, 41(1), 7-18. In press.

CILIP, (2007) Introduction to ethical principles and code of professional practice (n.d..) URL: http://www.cilip.org.uk/professionalguidance/ethics/introduction.htm [accessed 21.06.07]

Creaser, C. (2006) User surveys in academic libraries, New Review of Academic Librarianship, 12(1), 1-15.

Davies, J.E. (2002). What gets measured, gets managed: Statistics and performance indicators for evidence based management, Journal of Librarianship and Information Science 34(129), 129-133.

Fetterman, D.M. (1998) Ethnography: step by step, London: Sage, ISBN 0761913858 
Fox, C. (2002) The massification of higher education. In: Hayes, D. and Wynyard, R. eds. The McDonaldization of higher education, London, Bergin \& Garvey.

Hilder, P. and Pymm, B. (2008) Empirical research methods reported in highprofile LIS journal literature, Library \& information science research 30, 108114.

LISU (2006) LISU annual library statistics 2006. URL:

http://info.lut.ac.uk/departments/dils/lisu/downloads/als06.pdf [Accessed 21.12.2008].

Livingston, D. and Lynch, K. (2000) Group project work and student-centred active learning: two different experiences, Studies in Higher Education 25(3), 325-345.

Strauss, A. and Corbin, J. (1990) Basics of qualitative research: grounded theory procedures and techniques, London, Sage.

Sturges, P. (2008) Simple but effective LIS research: Why we need it, and how we can do it, Library and Information Research 32(100), 29-34.

Thornton, S. (2008) The workplace librarian, Library and Information Research 32(100), 35-42.

Walton, J. G. (2006) Learners' demands and expectations for space: in a university library: outcomes from a survey at Loughborough University, New Review of Academic Librarianship, 12(2), 133-149.

\section{The Occasion}

Joanna Bryant was awarded the LIRG Student Prize for 2008 for her MSc dissertation: An ethnographic study of user behaviour in Open3 at the Pilkington Library, Loughborough University.

\section{Acknowledgement}

Grateful thanks to Professor Graham Matthews and Dr Graham Walton of Loughborough University for their supervision and enthusiastic support. 